\title{
LAS FUERZAS ARMADAS SALVADOREÑAS
}

\author{
Héctor Samour
}

\section{Introducción}

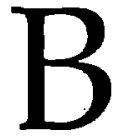

asta analizar críticamente la historia política del país para inteligir el papel preponderante que han jugado y juegan las Fuerzas Armadas en la configuración del sistema político salvadoreño. Ahora, en la etapa post-acuerdos, su papel seguirá siendo fundamental para garantizar la construcción de una verdadera democracia en nuestro país. No podemos obviar este hecho, por lo que se hace necesario analizar qué ha sido la Fuerza Armada, su origen y desarrollo, su función y comportamiento político. Este diagnóstico es necesario para vislumbrar las posibilidades que tiene aquélla para contribuir a la democratización y al arribo de una nueva sociedad fundada en la justicia, la libertad y, en general, en el respeto y plena vigencia de los derechos humanos, incluidos los derechos económicos y sociales de las grandes mayorías.

Hasta ahora, como lo demostraremos más adelante, el papel de la Fuerza Armada ha sido fundamentalmente negativo para la vida económica, social y política del país. El rasgo esencial del proceso político salvadoreño ha sido el militarismo, entendido como el desmedido influjo de los militares en las instituciones sociales y políticas, habiéndose convertido, en un poder fáctico situado por encima de cualquier otro poder fáctico. En este sentido, los militares salvadoreños han sido la negación misma de la democracia.

Si la nueva institucionalidad social, jurídica, política e ideológica que está emergiendo como consecuencia del cumplimiento de 
los acuerdos de paz no logra desmontar el secular militarismo que ha padecido el pais, todos los esfuerzos y luchas realizadas por las fuerzas populares en las últimas dos décadas habrán sido en vano y, lo que es más grave, se estarían de nuevo incubando condiciones subjetivas y objetivas para el resurgimiento de nuevos conflictos, con la imposibilidad de ir implementando las soluciones para los graves problemas nacionales.

De hecho, en la negociación, el FMLN percibió que era más importante y prioritario la democratización del sistema político que la solución de los graves problemas económicos y sociales o la cuestión de las estructuras injustas de propiedad y distribución. Que esto fue así lo prueba la mayor atención que se le dio en los acuerdos al tema Fuerza Armada-desmilitarización que al tema económico-social. El supuesto del FMLN para aceptar el acuerdo en esos términos se sustentaba en la idea de que en un marco de democracia real, con las garantías debidas para su participación política, y de otras fuerzas sociales y políticas progresistas, podría llevar adelante el proyecto popular por medios estrictamente políticos, sin necesidad del uso de la violencia o lucha armada. En esta línea, el FMLN entendió que con los acuerdos de paz estaba negociando un revolución aun no terminada, que debería ser completada en la lucha social y política a través de los espacios políticos abiertos a las fuerzas populares. Este fue el costo de no ganar la guerra y de no poder conquistar el poder a las inmediatas. De esta manera, se pospusieron las reinvindicaciones más sentidas de las mayorías populares a nivel económico y social para lograr avances a nivel político en términos de democracia real, con la esperanza de que a mediano y largo plazo, como producto del trabajo político, se podría avanzar hacia una democracia económica y social.

De acuerdo con esto, se entiende que si no se logran avances en la desmilitarización de la sociedad y en una verdadera reestructuración y democratización de la Fuerza Armada y su comportamiento político, las posibilidades de reactivación de los conflictos sociales y políticos con la consiguiente agudización de la crisis, son mayores. $Y$ es que, si bien es cierto que el principio último de la crisis y el conflicto armado radica en la "injusticia estructural" (Ellacuría), no es menos cierto que la guerra estalló como resultado de la ausencia de democracia producto de un sistema político autoritario 
signado por el militarismo. La realidad nacional estaba y está marcada por la demanda de democracia real; si ésta no se da, nada habremos avanzado. Esto lo deben entender todas las fuerzas sociales y políticas comprometidas con la democracia; éstas deben asumir con seriedad el camino trazado por los acuerdo de paz y aislar a todas aquellos grupos minoritarios conservadores que no quieren que este país cambie de una vez por todas. Se requiere de toda una acción democratizadora producto de la concertación y el consenso de las fuerzas democráticas, progresistas y revolucionarias que estimule una amplia movilización popular.

Ahora bien, el centro de esta necesaria acción democratizadora, lo constituye en primer término, el desmantelamiento del aparato de poder autoritario tradicional que, en el caso salvadoreño, radica en el boque oligárquico-militar que ha dominado tradicionalmente la vida política del país. Un elemento esencial de este bloque lo constituye la Fuerza Armada. Cuando hablamos de "desmantelamiento" del aparato de poder autoritario no estamos pensando en la destrucción del ejército - tesis que utilizan interesadamente los sectores de la ultraderecha civil y militar para justificar su intransigencia y su rechazo a los cambios, sino en la necesidad de la realización de transformaciónes en el seno de la Fuerza Armada actual para convertirla en una fuerza social democrática que no incida negativamente en el desarrollo del proceso político, tratando de hacer prevalecer sus intereses o los de los grupos oligárquicos. Queda todavía en pie la cuestión de si los cambios introducidos en la Fuerza Armada por los acuerdos - reducción, depuración, eliminación de los Batallones de Reacción Inmedita, nueva doctrina militar, eliminación de las defensas civiles, etc- son suficientes para garantizar su comportamiento democrático permanente y eliminar su pretensión tradicional de querer convertirse en árbitro de los asuntos nacionales a través de intervenciones militares o golpes de estado.

Diversos estudios sobre la transición de dictaduras a democracias señalan que el momento crucial en el paso de un gobierno autoritario a uno democrático no estriba necesariamente en la retirada del ejército a los cuarteles, sino en el cruce del umbral más allá del cual nadie puede intervenir para revertir los resultados del proceso político formal (ver Przworski, 1986: 6, 39-40). En este senti- 
do, la democratización es un proceso de sometimiento de todos los intereses a la competencia y donde no existe una aparato de poder autoritario capaz de impedir que se produzcan ciertos resultados políticos ejerciendo un control no sólo ex ante, sino también ex-post sobre la sociedad (ibid.). Desde esta perspectiva, las "democracias tuteladas" serían ejemplos de regímenes autoritarios. Aquí los militares evitan el ejercicio directo del gobierno y se retiran a los cuarteles, se realizan elecciones, se institucionalizan las libertades políticas a través de las cuales los conflictos pueden ser tratados en forma abierta. Pero son regímenes autoritarios porque las fuerzas armadas continúan amenazando, listas para caer sobre aquél o aquéllos que vayan demasiado lejos atentando contra sus valores e intereses (ver O'Donnell y Schmitter, 1988). En otras palabras, el aparato de poder conserva aquí su capacidad para intervenir y corregir estados de cosas que considera "indeseables".

De acuerdo a esto, no podemos afirmar por ahora si el resultado del cumplimiento de los acuerdos de paz posibilitará en El Salvador una democracia real o una democracia tutelada; si la actual transición consiste en una mera liberalización del sistema politico o posibilitará una real democratización. El punto clave para discernir esta cuestión es ver hasta qué punto las transformaciones surgidas por los acuerdos y las nuevas instituciones que se van creando posibilitan las condiciones para que no sea posible el retorno del autoritarismo y el militarismo.

Por liberalización entendemos aquí una apertura controlable del espacio político, que depende siempre de la compatibilidad de los resultados políticos con los intereses y valores del aparato de poder autoritario. El resultado final de un proceso de liberalización es una "democracia tutelada", es decir, un régimen que tiene unas instituciones competitivas, formalmente democráticas, pero en el cual el aparato de poder (generalmente reducido a las fuerzas armadas) conserva su capacidad de veto sobre los resultados del proceso político y donde las fuerzas políticas rivales eligen estrategias, teniendo en cuenta la amenaza de los poderes fácticos en concreto el de una intervención militar, y el miedo a ella. En cambio, en una democracia política real, su rasgo esencial es la incertidumbre referencial (O'Donnel y Schmitter, o.c). Esto quiere decir que los resultados del proceso político están hasta cierto punto indeterminados con 
respecto a las posiciones que ocupan los participantes en todas las relaciones sociales, incluyendo las relaciones de producción y las instituciones políticas. La cuestión fundamental aquí es que nadie puede estar seguro del triunfo de sus intereses en última instancia. Nadie puede modificar los resultados del proceso "ex post" y todos se someten a la competencia y a la incertidumbre. Este rasgo de la democracia no excluye, por ejemplo, que unos cuanto militares organicen una conspiración y traten de derrocar a las instituciones democráticas. Sin embargo, en una democracia, los militares no tienen la capacidad organizada para derrocar instituciones democráticas y todos los actores sociales y políticos que someten sus intereses a la competencia no tienen por qué prever sus reacciones.

En la actual situación en que nos encontramos no podemos afirmar con certeza cuál sea el término de la transición abierta por los acuerdos de paz: si una democracia tutelada o una democracia real. Uno de los puntos claves aquí es la futura estructura de la Fuerza Armada y su comportamiento político; su conversión a una fuerza social que cumpla realmente lo que le prescribe la Constitución Política, su sumisión real al poder civil, su apoliticidad, su profesionalismo democrático, la circunscripción de sus funciones a la defensa de la soberanía y del territorio nacional y su no intervención en el proceso político. El desenlace en uno u otro sentido depende de factores internos y externos.

Internamente se hace necesario configurar una "alianza antiautoritaria" y "antimilitarista" —que no significa anti-Fuerza Armada- (ver Echeverría, S. 1990: 733) que vaya modificando la correlación de fuerzas en favor de la democracia; se trata de un pacto entre las fuerzas económicas, sociales y políticas comprometidas con la democracia que, sin desvincularse de sus propios intereses y proyectos, realicen las acciones necesarias para erradicar definitivamente el régimen autoritario y el militarismo, posibilitando la creación y consolidación de instituciones democráticas como marco dentro del cual compitan por la consecución de sus intereses y sus proyectos de sociedad, superando la mera liberalización política y construyendo una genuina democracia, con el rasgo fundamental que apuntabamos anteriormente. En esta alianza no hay razón para que se excluya a los oficiales de la Fuerza Armada no comprometidos en la compción y las graves violaciones de los dere- 
chos humanos, como tampoco a los sectores empresariales. A este esfuerzo de interés nacional deberían abocarse, a corto plazo, principalmente los partidos políticos, entre otros, posponiendo sus intereses electorales y electoreros inmediatos, las ambiciones personales de los potenciales candidatos a los cargos públicos, teniendo en cuenta la fragilidad del proceso político en la actual transición.

Externamente, se hace necesario, al menos a corto plazo, el tutelaje del proceso por parte de las Naciones Unidas y de la Comunidad Internacional.

En cualquier caso, el elemento clave del proceso democratizador en El Salvador será la misma capacidad de la Fuerza Armada para autotransformarse y asumir los retos que enfrentará en el nuevo escenario nacional, regional y mundial después de la extinción del conflicto este-oeste y la desaparición de la "guerra fría". Determinar esta capacidad e identificar las potencialidades de su transformación hacen necesario que intentemos estudiar la estructura y el comportamiento de las fuerzas armadas salvadoreñas tal y como se han configurado históricamente. A ello dedicaremos los siguientes apartados.

\section{El comportamiento de los militares salvadoreños.}

Steve C. Ropp (1986) ha llamado la atención sobre el hecho que Slas discusiones sobre los ejércitos en la región centroamericana muy pocas veces se fundamentan en una teoría explícita acerca del comportamiento militar y no hacen referencia al extenso material teórico elaborado durante las décadas de los 60 y 70 . Además, muchos de los análisis del comportamiento militar se realizan sin hacer referencia al contexto histórico de un país en particular o a toda la región en general. Por otra parte, muchos de los análisis contemporáneos de los militares centroamericanos extraen una serie de conclusiones acerca de las razones y motivaciones de su comportamiento y de la ubicación de las fuerzas armadas dentro del contexto macrosocial, pero sin estudiar las instituciones militares mismas; sólo se estudian las condiciones políticas, sociales y económicas nacionales de las cuales derivan su comportamiento las fuerzas armadas.

$\mathrm{Si}$ bien es cierto que el enfoque macrosocial juega un papel fun- 
damental en la elaboración de teorías del comportamiento militar, su defecto estriba en tender a minusvalorar la autonomía de las instituciones militares al señalar una serie de obstáculos limitantes de la acción militar que, de hecho, reducen a las fuerzas armadas a un simple instrumento controlado por un proyecto socioeconómico mayor. De acuerdo a Ropp, "no existe hoy por hoy un balance semejante entre los enfoques macrosociales y los institucionales" (o.c.:413).

Sin embargo, existe actualmente una reducida pero creciente serie de escritos de contenido teórico que analizan a las fuerzas armadas contemporáneas desde una perspectiva histórica y que nos permiten realizar una aproximación sobre los patrones del comportamiento militar de las fuerzas armadas salvadoreñas.

Una de estas teorías alude el "despotismo reaccionario" (ver Baloyra, 1986) producto de la instauración de repúblicas oligárquicas en el itsmo durante las "revoluciones burguesas" de 1870-71, las cuales dieron pie a economías agroexportadoras sustentadas en sistemas de mano de obra campesina coaccionada. Estas formaciones, según Baloyra, llegaron a predominar políticamente en El Salvador, Guatemala, y hasta cierto grado, en Honduras.

Estas repúblicas oligárquicas fueron resultado, en primer término, de las transformaciones económicas de finales del siglo XIX, las cuales acompañaron la introducción del cultivo del café y el surgimiento de una oligarquía cafetalera liberal que marginó a las élites rurales más tradicionales, la Iglesia Católica y la pequeña clase de comerciantes. La nueva oligarquía "la componían principalmente los oficiales de los ejércitos liberales, los políticos, los intermediarios entre estos grupos, los ladinos de clase media-alta, y en el caso de Guatemala, los inmigrantes alemanes" (Baloyra, o.c.: 299). La transformación de esta coalición oligárquica muy peculiar en otra de talante despótico reaccionario ocurrió en las décadas de 1920 y 1930, como resultado de las tensiones sociales y económicas engendradas por la gran crisis del capitalismo de aquella época.

Dado que la crisis económica no llevó a que los cafetaleros cuestionaran "su" modelo, tuvieron que buscar los mecanismos para que siguiera funcionando dentro del contexto de los años 30 . Esto pasaba, en primer lugar, por contener las demandas y la movilización popular por lo que las oligarquías tradicionales apelaron a 
integrantes de las fuerzas armadas para que restablecieran el orden por medio de la represión, entregándoles el control directo del gobierno a cambio de la conservación del modelo económico.

En El Salvador, el viejo orden civil oligárquico, roto por la crisis económica del comienzo de los 30 y la siguiente movilización política que culminó con la rebelión y matanza de 1932, fue restaurado como orden oligárquico por dictadores militares conservadores. Cuando la hegemonía económica, social y política de la oligarquía terrateniente fue incapaz para dirigir y dominar dentro del tradicional sistema político formalmente liberal-democrático, éste fue reemplazado por formas políticas dictatoriales militares como medio para conservar la dominación de la oligarquía cafetalera. Sin embargo, como señala Guidos Véjar, esta restauración del sistema dictatorial de dominación por el bloque oligárquico-militar no se realizó sin imprimirle al Estado una participación económica y sin "diseñar políticas de asistencia a las clases subalternas para que no se repitieran acontecimientos similares a los de 1932 y manteniendo cierto acercamiento a dichas clases" (1980: 141). En este sentido, si bien la dominación oligárquica había sido restaurada, ésta no se dio sin grandes modificaciones por lo que no se puede afirmar que fue una simple reafirmación del sistema oligárquico anterior. Sin embargo, la dirección política sólo podía estar en manos de los militares, pues la reconstrucción del modelo de acumulación anti-democrático sólo era posible a través de la fuerza castrense. "La reconstrucción del régimen autoritario, exclusivista, sólo era posible si se controlaba a las clases subalternas que saldrían afectadas, pero también si se controlaba a la fracción burguesa que sería otro grupo bastante afectado en la reconstrucción y re-dinamización del sistema económico cafetalero" (Ibidem: 152). El hecho fue que, como resultado de lo anterior, la dictadura personalista de Martínez fue evolucionando hacia el fortalecimiento de la institución militar como el más poderoso aparato de Estado (ver Mariscal, 1978).

El resultado de la crisis de los años 30 en Centroamérica no fue el fascismo clásico, tal como ocurrió con frecuencia en otros países de América Latina durante este período. La causa de esto fue, de acuerdo a Baloyra, "porque el aparato central del Estado estaba muy pobremente desarrollado" (o.c.: 306), por lo que el modo de domi- 
nación política adquirió la forma de un despotismo reaccionario semejante a los surgidos en Europa mediterránea bajo condiciones y presiones similares tal como lo describe Salvador Giner. Giner describe el despotismo reaccionario como un modo de dominación política en el cual: (1) Una coalición reaccionaria de terratenientes, e industriales y financistas ligados a ellos; (2) imponen un régimen politico exclusivista que pretende legitimar su control de la economía y el limitado pluralismo político; (3) en el cual el poder del Estado se deja en manos de una clase dependiente surgida de los estratos medios; (4) en el cual, además, se les niegan los derechos políticos a los potenciales opositores al régimen, y (5) en el cual la cooptación y la obediencia pasiva sustituyen al consentimiento activo de la población.

La teoría del despotismo reaccionario nos ofrece un modelo macrosocial del cual se pueden deducir las características del funcionamiento y el comportamiento de los militares. El elemento clave aquí se reduce a la relación precisa en cada sistema de las fuerzas armadas con el Estado. En los sistemas despóticos reaccionarios, la existencia de un Estado débil sugiere que los militares mantendrán nexos estrechos con miembros de la coalición reaccionaria. En el caso de El Salvador, parece ser que los militares, o algunos de ellos cuando menos, responden más a los intereses de esta coalición que a cualquier conjunto de intereses nacionales.

Se podría cuestionar a esta teoría el que los militares hayan tomado control del poder político en nombre de la oligarquía cafetalera en la década de 1930. Por lo menos, en el caso de El Salvador, esto no parece ser tan claro. Guidos Vejar sostiene que sería un error "considerar que el ejército era un bloque homogéneo y con un pensamiento unitario o que una sola facción podía influír sobre todo el cuerpo castrense" (o.c.: 124). Desde 1912, el ejército experimentó una aceptación paulatina entre los sectores del capital, que en un principio eran reacios a aceptar a este grupo que se nutría de otras clases distintas a la clase propietaria (ver Wilson, 1970). Entre 1927 y 1931, la "Escuela Militar" se transformó en una institución muy estable para la profesionalización del ejército. Entre sus objetivos estaba el de adiestrar a los soldados nacionales, dotarlos eficientemente en el dominio de la técnica militar y servir como sostén de la república democrática. De hecho, la institución se ha- 
bía convertido en un importante grupo de presión, aun cuando se mantenía sometido a las decisiones de la clase política. Su participación en la vida política del país había aumentado en el período de Romero Bosque a través de la creación de un consejo militar.

Para 1931, el ejército se había convertido en un canal que abría oportunidades para los sectores urbanos medios donde dominaba una tendencia ideológica modernizante. Muchos artesanos habían hecho carrera militar y la influencia de los sectores populares al interior del ejército, en esta época, no era despreciable. El golpe militar que derrocó al gobiemo de Araujo fue lidereado por jóvenes militares reformistas que respondían más a los intereses de la fracción burguesa y demás grupos que reinvindicaban una alternativa económica que sustituyera a la de la clase cafetalera. En el proceso del golpe, los militares reformistas perdieron el control del mismo y fueron sustituidos por militares representativos de los grupos oligárquicos tradicionales (ver Guidos Véjar, o.c.: 131-152).

Estos datos son importantes para ver las limitaciones de la teoría del despotismo reaccionario propuesta por Baloyra. En primer lugar, carece de una descripción detallada de la relación entre la formulación lógica y el comportamiento militar observado. En segundo lugar, la evidencia histórica muestra que el modelo "puede producir una perspectiva económicamente determinista y demasiada simplificada del comportamiento "militar" en El Salvador y Guatemala" (Ropp, o.c.: 416). Además de que el mismo autor reconoce que el modelo solo pueda tener utilidad explicativa limitada a estos dos paises.

Como señala Rouquié (1987), las fuerzas armadas salvadoreñas no han estado ligadas férreamente en una alianza permanente con ninguna fuerza social y política. Si bien las fuerzas armadas han actuado generalmente en concordancia con los intereses de grupos oligárquicos, también los militares han apoyado en determinado momentos algunas políticas tendientes a debilitar el dominio económico de la oligarquía. De hecho, las fuerzas armadas salvadoreñas han estado más abocadas a defender su posición de poder en el Estado y sus propios intereses corporativos que los de cualquier alianza con cualquier fuerza económica o social.

A. White señala que ha sido difícil o imposible de conocer la na- 
turaleza de la relación entre los oficiales militares en el control directo del Estado, y la élite civil; si "esta relación es simplemente voluntaria de parte del grupo de oficiales, correspondiendo a similitud de ideas; o si la riqueza de la élite civil juega un papel directa o indirectamente, asegurando que los oficiales no se desvíen mucho de los intereses de la élite... o si existen otras presiones ejerciendo influencia" (1983: 223).

En cualquier caso, lo que es claro es que no se puede afirmar un determinismo mecánico sino más bien un condicionamiento económico en el comportamiento de los militares, lo cual explicaría su relativa autonomía y aquellas acciones, en determinados momentos históricos, donde las fuerzas armadas se han desviado de los intereses generales de la élite civil o del gran capital. Este fue el caso, por ejemplo, cuando fue derrocado el dictador Martínez en 1944 por una alianza cívico-militar de intelectuales de clase media y jóvenes militares y que se caracterizó por su intento de reformismo modernizador, y que culminó en el pacto constitucional de 1950, donde se recogían las tendencias desarrollistas y reformistas de esa década (ver López Vallecillos, 1979).

Según López Vallecillos, "el ejército, a pesar de estar presionado y condicionado por el poder económico del gran capital, ha tratado de servir al Estado en la doble dirección originada en el pacto social de 1950. En más de una ocasión ha tratado de acercarse a los sectores populares en busca de implantar reformas económicas y sociales, de carácter redistributivo, pero sus empeños han sido frenados por los sectores del capital que controlan la gran propiedad agricola y modelan el destino económico y político del país" ( o.c.: 560).

Otra teoría sobre el comportamiento de los militares se puede encontrar en José Z. García quien se centra en la trayectoria económica observable en la sociedad salvadoreña con el objetivo de encontrar una explicación teórica general de los patrones de comportamiento de los militares. De acuerdo a este autor, en El Salvador no se requirió, durante el período de la independencia o de la post-independencia, la formación de "una estructura de gobierno altamente centralizada en un aparato represivo" (1982: 2). Entonces, ¿qué fue lo que llevó a la formación de un aparato militar altamente institucionalizado y represivo en El Salvador a finales del siglo XDX?. La respuesta de García es directa y clara: “La creación 
y el subsecuente comportamiento de los militares como una institución en El Salvador coincidió con el gradual desplazamiento del añil por el café como el principal recurso económico del país a fines del siglo XIX. Por cierto, la expansión de la producción cafetalera no hubiera sido posible sin la existencia de un eficiente aparato de coerción interna" (Ibidem).

La lógica económica dominante necesitaba de la existencia de una aparato de Estado centralizado y coercitivo que satisfaciera los requerimientos de tierra y mano de obra necesarios para la producción del café. Después de su vertiginosa introducción en la década de 1870, la expansión cafetalera necesitó de la apropiación de grandes extensiones ejidales en las cumbres volcánicas hasta entonces trabajadas por las comunidades indígenas. Por otra parte, la producción cafetalera exigía mucha mano de obra, lo que implicó nuevos métodos de organización humana para asegurar una fuerza de trabajo eficiente. De esta manera, de acuerdo a García, la expansión de la producción agrícola en El Salvador implicó una fuerte autoridad estatal centralizada capaz de imponer los cambios estructurales necesarios para la producción del café en gran escala. Congruente con esta tesis, Guidos Véjar (o.c.:64) sostiene que el proceso de tranformación social impulsado por los cafetaleros adquirió un carácter no-democrático, pues para su consolidación tuvo que irrespetar los derechos democráticos de otros grupos sociales. El proceso de expulsión territorial que sufrieron los indígenas se convirtió también en un proceso de expulsión del campo político y de prohibición para cualquier tipo de organización corporativa. "Todo intento de organización o protesta independiente por parte de las masas campesinas fue reprimido fuertemente" (Ibidem). Fue el ejército el que principalmente desarrolló las funciones represivas, acorde con los intereses de las fracciones del bloque oligárquico que impulsaban las pautas autoritarias. De hecho, el ejército como institución se convirtió en el más importante regulador de la vida rural y desplazó en el control de los campesinos y trabajadores agricolas a los terratenientes que anteriormente efectuaban una práctica clientelista con estos grupos.

Si bien el régimen político salvadoreño se autoconcebía como repúblicano y la Constitución establecía la división de poderes y el voto universal, en la realidad era un régimen autoritario y exclu- 
sionista (ver Martin, P.P., 1911).

A manera de contraste y como forma de verificar sus hipótesis, García sostiene que el auge de las principales actividades agroexportadoras en Honduras, durante la última parte del siglo XIX y a principios del siguiente, no se vio acompañada por el crecimiento rápido de las fuerzas armadas ni por la represión militar. García atribuye este hecho a los requerimientos de tierra y mano de obra del banano. A diferencia del café, la producción del banano no demanda gran cantidad de mano de obra y, por lo tanto, no hubo necesidad, como en El Salvador, de un fuerte aparato de Estado que garantizara un constante suministro de trabajadores para las plantaciones. Y como los dueños de las plantaciones bananeras eran casi exclusivamente extranjeros, la presión que ejercían los trabajadores en demanda de mejores salarios no afectaba los intereses económicos de las élites locales. Los costos de producción, en cuanto a la disponibilidad de tierra y mano de obra, no fueron cargados ni a las élites locales ni a las masas, por lo que ninguno de estos dos grupos tuvo interés fuerte en el proceso productivo principal. De acuerdo a García, como consecuencia de lo anterior, no surgió ninguna institución militar en Honduras hasta la década de 1950 y, cuando lo hizo, sus objetivos principales no estaban ligados a garantizar una forma específica de dominación económica como en el caso de El Salvador.

En definitiva, de acuerdo a la teoría de García, el principal factor que condiciona el comportamiento de las fuerzas armadas y que quizá incluso determina su existencia misma, no es tanto la presencia de una economía agroexportadora como un determinado tipo de actividad agroexportadora. Según el tipo de actividad, ésta podrá determinar las tendencias represivas o reformistas de las instituciones militares.

El punto fuerte de este modelo ligado al tipo de cultivo para la exportación es su intento de explicar tanto los orígenes como también la cronología del desarrollo de la institución militar, además de los diversos patrones de comportamiento militar, es decir, los diversos grados de represividad. Sin embargo, no está claro si la introducción del café a El Salvador está vinculada con los orígenes funcionales de los militares, o con los orígenes económicos, o con ambos. En otras palabras, aun si se aceptara que el surgimiento de la 
producción cafetalera como actividad económica básica se asocia temporalmente con la formación de instituciones militares nacionales, no necesariamente se tiene que deducir que la producción cafetalera requirió funcionalmente de la creación de tales instituciones militares para reprimir y controlar a los grupos campesinos. Como alega Ropp, "pudiera ser que el café proporcionara sencillamente a estos países suficientes ingresos fiscales para costear un ejército dedicado a otras funciones totalmente distintas, tal como la defensa del territorio nacional" (o.c.: 418). En abono a esta crítica está el hecho de que en El Salvador las funciones represivas y de control social de los campesinos fue confiada principalmente a la Guardia Nacional, fundada y entrenada por oficiales españoles en 1912; sus agentes y los llamados supernumerarios (agentes de la guardia contratados por los grandes hacendados) se encargaban de mantener el orden y proveer de seguridad a los terratenientes principalmente durante las temporadas de recolección del café (Memoria del Ministro de Defensa, 1942). También hay que mencionar aquí a los patrullas cantonales o escoltas militares bajo la dirección de los comandantes locales que han formado parte del llamado servicio territorial y a través del cual el ejército ha mantenido una presencia constante en las áreas rurales. El resto de las fuerzas armadas, la infantería y los batallones de artillería, han cumplido funciones más limitadas de represión y control político, por lo menos hasta finales de la década de los 70, donde la función represiva la vanguardizaban los cuerpos de seguridad y los escuadrones de la muerte ligados a ellos.

Otro problema que presenta el modelo de García es el referente a los patrones de comportamiento militar a través del tiempo. Aun si suponemos que su interpretación histórica es correcta, ¿puede su interpretación servir de guía para explicar el comportamiento militar actual?. Es posible que las funciones originales que los institutos militares desempeñaban ya hayan sido superadas o, si todavía se llevan a cabo, tal vez ya no las efectúan por igual y con la misma intensidad todas las ramas de las fuerzas armadas. La Contrainsurgencia en la última década en El Salvador involucró más en la represión a los oficiales del ejército regular por encima de la Guardia Nacional y de los otros cuerpos de seguridad, como la Policia Nacional, que eran los que tradicionalmente ejercían más 
intensamente tal función, como vimos anteriormente.

Una tercera perspectiva teórica que examina el papel de los institutos militares es la que se conoce como la del pretorianismo. El concepto más elaborado del pretorianismo se encuentra en Samuel Huntington (1968) y en Perlmulter (1977). Huntington argumenta que el comportamiento de las fuerzas armadas de cualquier país no puede entenderse mediante un estudio directo de las fuerzas armadas mismas. Más bien lo que se necesita es una perspectiva macrosocial que explique si los militares intervendrán o no en el proceso político y bajo qué condiciones. Perlmutter distingue entre "ejército pretoriano-árbitro" y "ejército pretoriano-gobernante". Las características de un ejército pretoriano-árbitro son:

"1. aceptación del orden social existente

2. voluntad de retornar a los cuarteles una vez que las disputas hayan sido resueltas;

3. inexistencia de una organización política independiente y del deseo de maximizar el gobierno militar;

4. preocupación por el profesionalismo militar;

5. tendencia a actuar tras la escena política como grupo de presión;

6. temor al castigo civil".

En cambio un ejército pretoriano-gobernante:

"1. rechaza el orden existente y cuestiona la legitimidad;

2. desconfía del gobierno civil y no tiene expectativas para volver a los cuarteles;

3. tiene una organización política, y tiende a maximizar el gobierno de los militares;

4. está persuadido que el gobierno de los militares es la única alternativa al desorden político;

5. politiza el profesionalismo;

6. actúa abiertamente en la política, y

7. tiene poco temor al castigo civil". 
Dentro de la perspectiva de Huntington, los países subdesarrollados manifiestan primariamente tendencias pretorianas, razón por la que el papel político de los militares es relevante en el tercer mundo. Aquí, las intervenciones militares son una de las tantas manifestaciones de la característica esencial en las sociedades subdesarrolladas: la politización generalizada de las fuerzas sociales y de las instituciones. En efecto, en tales sociedades, la política carece de autonomía y todo tipo de fuerzas sociales y grupos se ven envueltos en la misma. Según Huntington, "los países que tienen ejércitos politizados tienen también un clero politizado, universidades politizadas, burocracias politizadas, sindicatos politizados y empresas politizadas. La sociedad está desencajada, y no solamente los militares" (1968: 194).

Huntington distingue tres tipos de pretorianismo: pretorianismo oligárquico, pretorianismo radical y pretorianismo de masas. En el primero, las grandes familias terratenientes se han constituido en camarillas políticas rivales. La actividad política es pretoriana porque su práctica está limitada a las minorías privilegiadas, las cuales muestran poca preocupación por un interés nacional. El pretorianismo radical se da cuando empiezan a surgir clases medias y se opera una diferenciación social de clases en general, pero siempre bajo la continuada ausencia de instituciones políticas autónomas. Una caracteristica principal aquí es que los militares cambien con frecuencia de una política de apoyo conservador a grupos oligárquicos a otra de apoyo reformista en función de nuevos grupos emergentes de la clase media. Finalmente, el pretorianismo de masas surge cuando se llega a un nivel superior de diferenciación social y de clase. Esta fase se identifica con una movilización y activación de clases mucho más amplia a través de una multiplicidad de organizaciones de toda índole, tanto en las zonas urbanas y rurales, acompañadas por un creciente conservadurismo y un papel político mucho más protagónico de las fuerzas armadas.

El mismo Huntington utiliza el ejemplo de El Salvador en la década de 1940 como un caso clásico de militares reformistas que actuaron en función de una nueva clase media que emergía, desplazando a la oligarquía tradicional. Lo mismo se puede aplicar al golpe de estado de 1960 con la ascención al gobierno de la efímera y democrática Junta de Gobierno (1960-1961) y la consolidación del 
Directorio Cívico-Militar (1961-1962). De acuerdo a Castro Morán (1989), con esta intervención de caracter progresista, "la juventud militar se proponía dar énfasis al desarrollo social" tratando de darle continuidad al Régimen Económico contenido en la Constitución de 1950 (ver Proclama de la Fuerza Armada del 25 de enero de 1961). Como ejemplo del pretorianismo de masas puede aludirse al comportamiento autoritario y exclusionista de las fuerzas armadas a lo largo de toda la década de 1970 en el contexto de una aguda crisis política y económica acompañada de una amplia movilización de las clases subalternas y el surgimiento y desarrollo de las organizaciones político-militares que después configurarían al FMLN.

Un elemento fuerte y sugestivo del modelo pretoriano es su intento de explicar los diversos patrones de comportamiento militar, reformista o reaccionario, a través del tiempo, durante distintas etapas del desarrollo económico y social nacional. Pero no es útil para explicar los orígenes de los militares ni la cronología de su desarrollo institucional. Esto es una consecuencia del énfasis macrosocial en contraposición a otras consideraciones o factores que influyen en el origen y el desarrollo de los militares.

El modelo pretoriano también falla a la luz de datos que evidencian que ciertos cambios al interior de las fuerzas armadas centroamericanas sí influenciaron su comportamiento político durante las décadas de 1950, 1960 y 1970. En estas décadas, la autonomía relativa y las expresiones políticas de los militares iba aumentando, posibilitando la elaboración de programas y proyectos políticos que trascendían los interes de clase en la sociedad (ver Ropp, 1974 y 1982). Además, lo interesante en el caso de las fuerzas armadas salvadoreñas es su prominente poder político, su relativa autonomía, su capacidad para renovar su presencia en los altos puestos oficiales del poder del estado y legitimar su presencia dentro de la población, especialmente en las áreas rurales donde, hasta hace muy poco relativamente, ha vivido una gran parte de la población del país.

En general, como señala Ropp, las instituciones militares en toda América Latina presentan "la tendencia hacia una mayor autonomía relativa del Estado y sus mecanismos de control coercitivo" (1986:420). 
Finalmente, existen dos modelos que nos pueden clarificar aún más el comportamiento de los militares salvadoreños. Se trata del modelo de la seguridad nacional y de la perspectiva teórica que atribuye el papel de "gendarmes" del imperio a las fuerzas armadas.

El modelo de seguridad nacional se deriva esencialmente de los estudios de Alfred Stepan de los años 70 sobre Brasil y Perú. La creciente participación política de los oficiales brasileños y peruanos durante las crisis domésticas de la década de los 60 , motivó a Stepan a poner en tela de juicio muchas de las premisas de los estudios sobre la índole del profesionalismo militar. Contrario a lo planteado por Huntington, quien sostenía que la función de los militares del tercer mundo se tornaría más especializada en la medida que la defensa nacional fuera sustituyendo la preocupación por la política interna, Stepan plantea que las condiciones de subdesarrollo económico y la insurgencia guerrillera que imperaban en Brasil y Perú, aunadas a los esfuerzos estadounidenses por promover el profesionalismo militar a través de los programas de ayuda militar, en la práctica llevaron a un profesionalismo de naturaleza muy distinta. En vez de incrementar su especialización funcional, los militares comenzaron a preparar a sus oficiales en el aprendizaje de aspectos de seguridad interna que abarcaban todas la áreas de la vida social, económica y política. En lugar de independizarse las esferas de lo militar y lo político, "el nuevo profesionalismo condujo a la creencia de que existía una interrelación fundamental entre las dos esferas, con los militares asumiendo un papel clave al interpretar y resolver los problemas de política interior dados sus extensos conocimientos técnicos y profesionales en el manejo de los asuntos de seguridad interna: "El ámbito de la injerencia militar en ... los asuntos políticos se volvió ilimitada al grado de que el 'nuevo militar profesional' se tornó altamente politizado" (Stepan, 1976: 31).

En concreto, pues, la perspectiva de la seguridad nacional indica que un 'nuevo profesionalismo' comenzó a surgir en ciertos países centroamericanos durante la década de los 60 . Un nuevo profesionalismo que permitió a los oficiales involucrarse más activamente en la política debido a su creciente preocupación por la seguridad interna y el desarrollo económico nacional. En esta línea, Mariscal (1978) ubica la aplicación de la doctrina de la seguridad nacional 
en Centroamérica en la década de los 70 después de la guerra entre El Salvador y Honduras y el golpe que aquélla supuso al CONDECA (Consejo de Defensa Centroamericano). La doctrina de Nixon, inspirada en el informe Rockefeller y liberada de los escrúpulos democráticos y reformistas de la Alianza para el Progreso fomentó el desarrollo de la capacidad militar de los ejércitos nacionales para luchar contra el comunismo, de modo que se puediera evitar, en lo posible, la intervención directa estadounidense. Durante el gobierno de Nixon no sólo se reconoció a los regímenes militares como gobernantes legítimos, sino que incluso se fomentó el gobierno militar sobre el civil democrático siempre que el primero fuese más ventajoso que el segundo para los intereses estadounidenses (ver LaFeber, 1989: 265 ss).

En el enfoque de la doctrina de Nixon de 1969, Estados Unidos ya no actuaría como gendarme del mundo, sino que trabajaría estrechamente con aliados selectos, quienes actuarían como policías. "Los policías incluían al Sha de Irán en la ronda del Medio Oriente, los generales brasileños en la sudamericana y los regímenes militares en la centroamericana" (ibidem).

En este contexto, la ayuda militar estadounidense y los programas de entrenamiento para las fuerzas armadas centroamericanas y los cuerpos de seguridad aumentaron repecto a las décadas de los 60, dando base así para su fortalecimiento militar. En este período, las fuerzas armadas se convirtieron en el eje articulador del sistema político, responsables de la seguridad y del orden interno, redefinido teórica y técnicamente para la contrainsurgencia.

Una aplicación de la doctrina de la seguridad nacional al caso salvadoreño se encuentra en Tomás R. Campos (1979). Campos argumenta que esta perspectiva militar surgió de manera intensa en la década de los 70 y estaba conformada por varios elementos, muchos de los cuales entraban en contradicción con la Constitución política vigente hasta ese momento. Entre esos elementos, están:

1) la conservación de los valores de la cultura occidental como objetivo último;

2) la visión del mundo dividido en dos bloques antagónicos e irreconciliables: el bloque comunista y el bloque capitalista; 
3) anticomunismo como justificación ideológica para la defensa del sistema capitalista;

4) visión maniquea del mundo y de la realidad social, calificando de subversivo y comunista a todo aquello y aquellos que fueran contra el orden establecido;

5) definición de la democracia desde la seguridad interna y el anticomunismo;

6) atribución de la representación auténtica de la nación y del Estado a las fuerzas armadas;

7) absolutización del valor de seguridad, entendida como mantenimiento del "status quo";

8) la Fuerza Armada como la única garante de la seguridad, sobre todo cuando el orden se ve amenzado por la protesta popular;

9) sustitución del pueblo y de los Poderes del Estado por una estructura militar, convertida mistificadamente en depositaria de la soberania nacional;

10) la anulación práctica de los procesos electorales a través de elecciones manipuladas y fraudulentas y

11) la represión de las fuerzas populares que pretendan organizarse social y políticamente.

Como resultado de la teoría y la práctica de la doctrina de la seguridad nacional, en la década de los 70 se fue acentuando la militarización de la vida pública que se expresó, entre otras cosas, en una ocupación militar en áreas de la política, prohibidas por la Constitución. Si ya en la década de los 60 se había dado una militarización del proceso político, cuyos hitos importantes fueron la Proclama de la Fuerza Armada el 25 de enero de 1961 y la creación del CONDECA en 1964, el proceso de militarización en los 70 se fue concretizando en la ocupación de numerosos puestos de la administración pública, no sólo dentro del gabinete de gobierno, sino además en los principales organismos y entidades autónomas (ver Andino Martínez, 1979). En el gabinete de Sánchez Hernández (1967-1972) los militares ocupaban dos ministerios, el de Defensa y el de Trabajo y Previsión Social; dos Subsecretarías, la de Defen- 
sa y la de Agricultura y Ganadería, y la Secretaría Privada de la Presidencia de la República.

Con Arturo Armando Molina (1972-77) se incrementó el número de puestos controlados por militares con tres ministerios: Defensa, Interior y Agricultura y Ganadería; la Sub-secretaría de Defensa; las Secretarías Privada, Particular y de Información, de la Presidencia de la República. Con los dos primeros ministerios se pretendía tener un estricto control de la sociedad; mientras que el Ministerio de Agricultura y Ganadería intentaría fallidamente realizar la Transformación Agraria.

Con Carlos Humberto Romero (1977-79) se ponía en manos de los militares los Ministerios de Defensa, Interior, Trabajo y Relaciones Exteriores. Asimismo conservaban los militares la Sub-secretaría de Defensa, y las Secretarías Privada y de Información de la Presidencia. Sin embargo, donde se produjo una mayor ocupación militar fue en los organismos y entidades autónomas. Los militares controlaban la dirección del Instituto de Colonización Rural, el Comite de Emergencia Nacional, la Dirección General de Estadística y Censos, la Comisión Nacional de Asuntos Limítrofes y Territoriales del Ministerio de Relaciones Exteriores, ANTEL, INSAFI, ISTA y la Dirección General de Transporte Terrestre. Además tenían representantes en los Consejos de Dirección en Aerolíneas de El Salvador S.A., CEPA, FOCCO, Compañía Salvadoreña del Café S.A., CEL, ANTEL, INSAFI, Banco Central de Reserva, Cooperativa de Crédito Rural Limitada, Banco de Fomento Agropecuario y la Financiera Nacional para la Vivienda. Además, de 27 representaciones diplomáticas en el extranjero, 10 estaban regentadas por militares (ibidem).

Por otra parte, también en este período se intensificó la formación profesional de los oficiales a través de la Escuela del Estado Mayor y de cursos de especialización en el extranjero, donde el rubro de "Seguridad Interna" era el más solicitado y que respondía al planteamiento y opción política de la Fuerza Armada en función de los objetivos de la seguridad nacional (Ibidem).

Después del golpe de estado del 15 de octubre de 1979, la Fuerza Armada protagonizó el proceso político durante el período del gobierno de facto. Fue la oficialidad la que dio el golpe de estado 
y fue ella misma la que llamó a civiles. La crisis de la primer Junta también fue conducida por la institución armada (ver Andino Martínez, 1982) con la negativa del COPEFA (Comité Permanente de la Fuerza Armada) al ultimatum presentado por los miembros civiles de la Junta y del Gobierno, iniciando así el abandono del espíritu del 15 de octubre y produciendo la derechización del proceso político. Depués se realizó el pacto con el partido Democráta Cristiano donde la institución armada aceptó incluso condiciones más exigentes que las del gobierno anterior en materia de reformas; sin embargo, en el marco de una crisis de poder y una situación de guerra civil donde el ejército aplicó acciones de cerco y aniquilamiento, además de una intensa y extensa represión, se convocó a las elecciones de marzo de 1982.

El período comprendido entre el golpe de estado y la convocatoria a elecciones fue un espacio en el que se intentó una recomposición del bloque gobernante y de la estrategia militar (ver Echeverría, o.c.). Aquí la militarización de la sociedad llegó a niveles nunca vistos antes (ver Torres Rivas, 1986). Por último, y tras un compromiso público del ejército de garantizar las elecciones y respetar sus resultados, el Alto Mando "sugirió" la nominación del Dr. Alvaro Magaña como Presidente Provisional de la República, debido a una ruptura del pacto contraído entre los partidos de oposición.

De esta manera, en todos estos pactos, las fuerzas armadas se convirtieron en gestoras de alianzas con grupos y partidos, reservándose siempre una cuota de poder, no sólo en la aprobación de los desginados para ocupar los cargos administrativos, sino también en la introducción en algunos de ellos de personas propuestas por ellas y en la ocupación de puestos claves en el gobierno y en los organismos autónomos. Sin embargo, si bien el estamento militar fue protagonista en todo este proceso, cada vez se iba evidenciando una subordinación cada vez mayor a las directrices del gobierno estadounidense, tanto a nivel político, ideológico, diplomático y militar. Esto fue una constante a lo largo de la década de los 80 .

A principios de la década anterior se podían distinguir diversos sectores y tendencias al interior del ejército. Andino Martínez (1982) distinguía tres posturas $u$ opciones diferentes al interior de la institución castrense: 1) la tendencia más dura y militarista; 2) la tendencia profesionalizante más ligada a los intereses estadouniden- 
ses y 3) la tendencia progresista o reformista, en principio favorable a una negociación entre ambas partes. Sin embargo a medida que se profundizaba el conflicto, estas tendencias se fueron desvaneciendo y el estamento militar se fue cohesionando internamente. Existen una serie de variables o elementos para explicar esta cohesión interna, pero un elemento nuevo y fundamental fue que, por primera vez en su historia, el ejército tenía frente a sí a otro ejército que le disputaba su poder y su predominio. En este sentido, la guerra fue un elemento estratégico básico y aglutinante en cuanto una derrota militar suponía la disolución de las fuerzas armadas como institución. Conviene resaltar aquí que un elemento aglutinante a nivel psicológico en la mentalidad de los militares salvadoreños es la permanencia de la institución. A nivel ideológico-político, la doctrina de la seguridad nacional también jugó un papel fundamental. La ideología, tanto del gobierno norteamericano como de la institución armada era agresivamente anticomunista y de Seguridad Nacional y en grado exacerbado en los inicios de las administraciones republicanas estadounidenses de la década pasada.

La otra perspectiva teórica a la que aludíamos, y que está vinculada de alguna manera a la anterior, es la que atribuye el papel de "gendarme" a los militares centroamericanos enfatizando el hecho de que los ejércitos de la región no son más que policías fuertemente armados al servicio de los intereses de una potencia extranjera, en este caso, de los intereses norteamericanos. De acuerdo a esto, sus orígenes institucionales no radican primariamente en los requerimientos de grupos socio-económicos internos, sino en la necesidad de la gran potencia por controlar y ejercer influencia permanente sobre los grupos locales y la nación en su conjunto.

Louis A. Pérez Jr.(1985) sostiene que una adecuada comprensión de la presencia histórica norteamericana es importante para explicar el comportamiento militar en la región centroamericana. Según él, "muchas de estas fuerzas armadas surgieron directamente como la expresión institucional del sistema hegemónico", por ello "son los gendarmes del imperio, cada uno de ellos hecho responsable de la seguridad nacional, pero todos preparados para actuar colectivamente para conservar el consenso imperial regional".

La perspectiva de Pérez pone mayor énfasis en la importancia colectiva del establecimiento de fuerzas policíaco-militares en la 
región por parte de Estado Unidos. No se trata sólo del hecho de que Estado Unidos creó estas instituciones en Cuba (1898-1902), Panamá (1904), República Dominicana (1916-1930), Haití (1915-1934) y Nicaragua (1927-1932), sino también el de instrumentalizarlas colectivamente como una barrera en contra de la penetración extranjera. Esta integración regional tuvo más tarde una expresión institucional, en el contexto de la guerra fría, mediante tratados de alianzas formales, tal como el CONDECA (1964) que fue incorporado al sistema de defensa de Estados Unidos en 1965. Esta promovió la homogeneización de la organización, entrenamiento, armas y equipo de las fuerzas armadas centroamericanas y la realización de maniobras conjuntas militares. Esto no dejó de tener consecuencias para las posibilidades reformistas de los militares centroamericanos. La indoctrinación política, por parte de Estados Unidos, a los ejércitos centroamericanos, sobre los males del comunismo contribuyó a incrementar su temor ante los grupos políticos que abogaban por reformas y democracia real. El énfasis en la propaganda anticomunista sirvió solamente para reforzar y promover el conservadurismo a la vez que inspiraba una creciente desconfianza a todo tipo de reformismo o democratización de las estructuras políticas. El aspecto de propaganda política del entrenamiento del Comando Sur aumentó la tendencia de los oficiales militares centroamericanos a justificar el uso de la represión bajo el pretexto de frenar el comunismo (ver Monteforte Toledo, 1972).

$\mathrm{Si}$ bien en el nuevo contexto actual de ausencia del conflicto este-oeste, la teoría de los "gendarmes del imperio" ya no tiene un asidero histórico-real, sin embargo, nos da una serie de elementos que nos permiten entender el comportamiento de las fuerzas armadas durante las décadas 70 y 80.

En el caso salvadoreño, si bien la influencia norteamericana en la formación y comportamiento de la Fuerza Armada no fue relevante después de la Segunda Guerra Mundial, en las últimas dos décadas, sobre todo en la de los 80 , se vio aumentada vertiginosamente como consecuencia de la agudización de la crisis y del conflicto. En este periodo, el grueso de la asistencia de Estado Unidos a El Salvador se enfocó al fortalecimiento del ejército para su mejor preparación para la guerra de contrainsurgencia y el abastecimiento total de sus medios bélicos; la asistencia propiamente eco- 
nómica se dedicó a inyectar capital para equilibrar la balanza de pagos, financiar parte de las importaciones y apoyar a aquellas fuerzas políticas - como la Democracia Cristiana- que sostuvieran la "fachada democrática" del proyecto militarista contrainsurgente (ver Ellacuría, 1988).

De hecho, la presencia militar estadounidense aumentó considerablemente como parte de su política hacia Centroamérica. Desde que la administración Reagan asumió el poder en 1981, su objetivo estratégico fue restablecer la hegemonía estadounidense en la región derrotando a los movimientos revolucionarios y fortaleciendo a gobiernos afines, tratando de demostrar así, en una zona de dominación tradicional, la nueva determinación estadounidense de "impedir el avance del comunismo en el mundo". Sin embargo, la forma de implementar ese objetivo varió sustancialmente a partir de 1983 ante la evidencia de que el esfuerzo hasta entonces realizado era incompleto e insuficiente: mientras al principio la administración Reagan apostaba a una victoria a corto plazo en El Salvador para, a partir de aquí, emprender acciones más decisivas contra Nicaragua, al cabo de dos años de esfuerzos infructuosos decidió profundizar su presencia política y militar en toda el área centroamericana, intentando resolver regionalmente la crisis. Ello dio origen, en primer lugar, a un aumento sustancial de la presencia militar, tanto para conducir los conflictos como para tener la alternativa de intervención en ellos; en segundo lugar, a un aumento cuantioso de la ayuda a la región y, en tercer lugar, a una mayor actividad política para estabilizar a los gobierno afines y hacerlos participar junto a Estado Unidos. En este último aspecto, existía el reconocimiento explícito de que la crisis no podía tener una solución puramente militar sino que era necesario atender también a los factores políticos y económicos de inestabilidad, sin perjuicio de la estrategia militar como centro de la acción estadounidense.

La estrategia de regionalización del conflicto seguida por Estados Unidos en Centroamérica se pueden resumir en cinco puntos (ver CINAS, 1986):

1. puesta en marcha de una nueva estrategia de contrainsurgencia en El Salvador, que a diferencia a la seguida en 1981 y 1982, atendía mucho más directamente a factores políticos y económicos, combinándolos con la asunción mucho más 
directa por parte de Estados Unidos en la planificación y la conducción de la guerra;

2. la escalada en la presión militar en contra de Nicaragua, utilizando como instrumento principal a las fuerzas contrarrevolucionarias instaladas en Honduras y Costa Rica con el objetivo de derrocar al gobierno Sandinista;

3. incremento de la presencia militar, con tres objetivos: asumir un papel más relevante en la conducción de las operaciones militares en El Salvador; presionar al gobierno Sandinista y respaldar a Honduras, base fundamental de la "contra", y contar con la opción de intervención directa como último recurso;

4. la democratización formal (liberalización política) de los países de la región, a través de gobiernos civiles estables que respaldaran la política estadounidense, $y$

5. la neutralización de otros actores externos inclinados a la negociación política, tratando de que su acción fuera, en lo posible, funcional a los intereses norteamericanos.

En este período, las fuerzas armadas salvadoreñas se convirtieron en el aliado más confiable de los Estados Unidos para llevar adelante la guerra de baja intensidad, cuyo objetivo principal era aplastar militarmente al FMLN o, por lo menos, reducirlo a una fuerza política controlable. En tanto el proyecto norteamericano de baja intensidad era un proyecto fundamentalmente militarista y no político, promovió crecientemente la militarización y el militarismo tradicional del sistema político salvadoreño. En este contexto, todos los pactos que las fuerzas armadas realizaron con diversas fuerzas políticas, sociales y económicas sirvieron para reforzar su predominio militar en el estado y preservar su autonomía institucional. Consecuentemente, si bien las fuerzas armadas toleraron una apertura política controlada, incluyendo la elección de líderes civiles, conservaron su capacidad para intervenir contra aquello que consideraran situaciones indeseables y que atentara contra sus intereses y los de sus patrocinadores.

Este continuo y acrecentado control militar del aparato de estado ha sido un obstáculo insalvable para la democratización plena 
del país, en el sentido que señalábamos en la introducción. $Y$ es que la prioridad, en el proyecto estadounidense de contrainsurgencia, no eran primariamente ni las reformas ni la instauración de la democracia, sino la aniquilación de movimientos insurgentes. Las reformas o la liberalización y modernización del sistema político se supeditaban a aquel objetivo central.

Desde esta perspectiva, Ellacuría afirmaba que todos los avances democráticos en El Salvador tenían un carácter de "fachada". "No se puede hablar de democracia profundamente real cuando las necesidades básicas de la mayor parte de los ciudadanos están insatisfechas, cuando hay una permanente y sistemática violación de los derechos humanos, cuando el poder judicial carece de consistencia, independencia y eficacia, cuando el poder militar no está absolutamente sometido al poder civil, cuando no hay opción segura para todas las tendencias políticas, cuando los partidos políticos no tienen internamente estructuras democráticas, cuando el poder fundamental de decisión está fuera del propio Estado" (1988: 311-327).

La asistencia militar y el entrenamiento estadounidense a las fuerzas armadas se expandió dramáticamente, dando por resultado un enorme crecimiento de las mismas, la modernización de su arsenal militar y un dramático incremento de su poder de fuego y capacidad de combate. Si bien la ayuda estadounidense fue adecuada para evitar una victoria del FMLN, no fue suficiente para asegurar una victoria militar total. Este continuado "empate" militar fue uno de los elementos fundamentales que determinó la posibilidad de la apertura del diálogo-negociación que desembocaria en los acuerdos de paz a finales de 1991.

Además de incrementar la capacidad de combate de los militares, la asistencia estadounidense estaba también dirigida a configurar un profesionalismo democrático dentro de las fuerzas armadas. Todavía no está claro hasta qué punto los oficiales estadounidenses le dieron importancia o se aplicaron negligentemente a realizar este objetivo, pero lo que sí es claro es que el progreso en esta materia fue deficiente. Esto se reflejó en el involucramiento de los militares en graves violaciones a los derechos humanos y en una persistente corrupción dentro de la institución castrense. Esto se ha visto favorecido por la impunidad de los cuerpos oficiales del 
ejército salvadoreño.

Esta impunidad hay que entenderla sobre la base que los oficiales del ejército salvadoreño conforman una élite que cuenta con una posición autónoma dentro de la estructura nacional de poder. Los que provienen de una misma generación de la Escuela Militar (lo que es conocido como el sistema de "tandas") son promovidos en bloque al rango superior de coronel, sin tomar en cuenta sus méritos. Esta práctica impide la delimitación de la responsabilidad militar, lo que conlleva consecuentemente la impunidad ante los abusos en los derechos humanos, la tolerancia a la incompetencia militar y la generalización de la corrupción, que hasta ahora ha resultado incontrolable (ver Schwarz, 1991 y Millman, 1989).

El hecho es que los intereses de la tanda con frecuencia prevalecen sobre los del ejército como un todo y aun están por encima del gobierno civil. Incluso se ha llegado al grado donde la "tanda" dominante dentro del ejército asume mistificadamente la representación de los intereses de toda la institución militar como un todo e incluso de la nación. Las "tandas" se han integrado a agrupaciones personales, gremiales y profesionales y se mantienen unidos para darse ayuda mutua sobre la base de la lealtad "ciega" y el compadrazgo. La férrea lealtad dentro de las mismas ha provocado que se impidan o se obstaculicen la realización de reformas institucionales y ha dificultado que los líderes civiles puedan tener influencia y control. Como ejemplo de esto, puede citarse el caso altamente publicitado de los secuestros de empresarios en 1986, y donde tres oficiales pertenecientes a la "tandona" (la numerosa generación de oficiales graduados en 1966) estaban implicados. A pesar de toda la evidencia y de todos los esfuerzos del entonces Vice-Ministro de seguridad pública por enjuiciarlos, sus compañeros de tanda, incluyendo al Ministro de Defensa René Emilio Ponce, intervinieron para encubrirlos. Incluso, uno de los oficiales implicados, el coronel Mauricio Staben, retornó al servicio activo como comandante del batallón élite Arce (ver Schwarz, 1991: 28-29).

La falta de progreso en la profesionalización de las fuerzas armadas también se ha reflejado en la ausericia de una línea clara de mando dentro de los militares. Un estudio realizado por la cámara bipartidista del Congreso de Estados Unidōs señala que los militares salvadoreños no siguen una cadena de mando clara y definida, 
sino que funcionan a través de un complejo sistema de consenso dentro de las tandas, controlado por los oficiales del Alto Mando (Barriers to Reform: A profile of El Salvador's Military Leaders, Mayo de 1990).

Las poderosas tandas siempre se han opuesto a los esfuerzos realizados por la Embajada estadounidense, por los asesores norteamericanos y por los propios oficiales salvadoreños entrenados en Estados Unidos, que pretendían reformar y profesionalizar a la Fuerza Armada. Un estudio realizado por cuatro tenientes coroneles estadounidenses señala que los esfuerzos encaminados a cambiar las características de los cuerpos oficiales salvadoreños para implementar un modelo más profesional han tenido resultados muy pobres (ver Bacevich et al., 1988).

Además, la cuantiosa ayuda militar estadounidense ha sido absorbida por una amplia red de corrupción, protección e impunidad (ver Millman, 1989). De hecho, la ayuda militar estadounidense ha servido para fortalecer aún más a la élite militar salvadoreña potenciando la supremacía militar en la esfera política, minando las posibilidades de transformar democráticamente la sociedad .

Millman (o.c. :47, 95,97) prueba la práctica extensiva de los oficiales de agregar nombres de "soldados fantasmas" - plazas ficticias- en las nóminas de las brigadas y, de esta manera, poder incrementar sus fondos mediante el desvío de salarios. Según Millman, cada año los 14 máximos jefes militares se repartían veinte mil salarios entre ellos; si cada paga alcanza la suma de 100 dólares mensuales, estaríamos hablando de unos 24 millones de dólares que se desviaban para ese fondo "sucio". Esta práctica corrupta también ha incidido en la ineficiencia de la estructura de mando militar con respecto a los comandantes de brigada quienes han actuado como conductores de la guerra en los departamentos bajo su control. Un ejemplo de esto fueron las dificultades surgidas para implementar un programa nacional de entrenamiento básico en la instalaciones del CEMFA (Centro de Entrenamiento Militar de la Fuerza Armada). A pesar de que el Ministro de Defensa giró una "Orden General" para tal efecto, el plan fue resistido por los comandantes de brigada departamentales ya que con ello perdian el acceso a una importante fuente de corrupción: los fondos para proveer a los reclutas de salarios, comida y uniformes. 
Otra fuente de poder del ejército han sido los fondos del llamado Instituto de Previsión Social de la Fuerza Armada (IPSFA). Dicho fondo, que hasta 1990 superaba la cifra de 100 millones de dólares, de hecho ha convertido al ejército en la "mayor fuente de capital líquido del país" (Tbidem). El IPSFA se ha convertido en un conglomerado multimillonario en dólares que financia hipotecas, administra sus pequeños negocios propios y desarrolla proyectos de bienes raíces, incluyendo grandes propiedades como un centro comercial y una torre de 13 pisos destinadas para las oficinas del nuevo Banco de la Fuerza Armada. Si este banco abre sus puertas, como está planeado, afirma Millman, "el equilibrio del poder entre los militares y los civiles quedará alterado para siempre" (ibidem). Hay que tener presente que el ejército se ha rehusado a obedecer las órdenes del presidente para depositar los fondos del PSFA en el Banco Central de Reserva.

En materia de derechos humanos, el documento del Congreso estadounidense citado anteriormente, señala que 14 de los 15 oficiales de mayor rango del ejército salvadoreño llegaron a esos cargos a pesar de los comprobados abusos en los derechos humanos de los civiles, llevados a cabo por tropas bajo su mando. Esos abusos incluyen asesinatos, violaciones, torturas y encubrimientos de violaciones a los derechos humanos. Dentro de los nombres que se daban están el del jefe del Estado Mayor, el ministro y el viceministro de la Defensa, el de las cabezas de las tres fuerzas de seguridad y cinco de los de las seis mayores brigadas. El documento afirma: "la promoción a rangos superiores de tantos oficiales cuyas tropas han cometido abusos en materia de derechos humanos en repetidas ocasiones, así como que no se haya enjuiciado ni a los jóvenes oficiales por esos abusos, sugiere que existe muy poca responsabilidad en el nivel más básico".

\section{Conclusión: Los militares después de los acuerdos de paz.}

$\mathrm{Z}^{1}$ punto a considerar aquí es determinar en qué sentido los armadas y crean las condiciones para cambiar las relaciones civiles-militares en una dirección realmente democratizadora de la vida política del país, eliminando la militarización y el militarismo. 
En el papel, los acuerdos representan un avance en la reducción de las prerrogativas institucionales de los militares. Bajo los términos de los acuerdos, el rol constitucional y la doctrina de las fuerzas armadas están completamente redefinidas. La responsabilidad primaria de los militares es la defensa nacional; su papel en la seguridad pública está limitada a situciones de emergencia nacional y únicamente bajo un control estricto del órgano ejecutivo. La doctrina de las fuerzas armadas está redefinida haciendo hincapié en la preeminencia de la dignidad humana y los valores democráticos, el respeto a los derechos humanos y la subordinación a las autoridades constitucionales.

Además, los acuerdos suprimen las fuerzas de seguridad y crean una una nueva policía nacional civil bajo el control ejecutivo. Adicionalmente disuelven la Dirección Nacional de Inteligencia bajo el control militar. El sistema educativo de las fuerzas armadas será completamente reconstituido incorporando dentro de su programas de entrenamiento la nueva misión constitucional y la nueva doctrina. Un nuevo consejo académico para la escuela militar, compuesto por civiles y militares, está encargado de diseñar el curriculum, los procedimientos de admisión y la designación de sus facultades, capacidades y otros requisitos.

Los acuerdos también señalan la depuración de los cuerpos oficiales, asumiendo las recomendaciones de la comisión especial ad hoc, compuesta por tres prominentes salvadoreños, y la reducción de las fuerzas armadas. El plan de reducción incluye la disolución de los batallones de combate especializados (Batallones de Reacción Inmediata), las unidades de la defensa civil y las patrullas cantonales.

Sin duda, si son implementados completamente, los acuerdos podrían conducir hacia una tranformación significativa de las fuerzas armadas y de las relaciones civiles-militares que han predominado hasta ahora. Sin embargo, es importante mencionar una serie de limitaciones. En primer lugar, no hay mención en los acuerdos sobre la administración de militares en instituciones claves del estado ni sobre la autonomía interna de las promociones de las tandas. En segundo lugar, la creación del consejo académico para la Escuela Militar no se aplica para otros programas de entrenamiento, los cuales aparentemente no estarán sujetos al control civil. En tercer lugar, los acuerdos no señalan la posibilidad de designar un 
civil como ministro de Defensa, un elemento clave si se quiere propiciar la supremacía civil sobre los militares. Finalmente, si bien los acuerdos se refieren a la necesidad de acrecentar el control legislativo y judicial sobre el comportamiento de los militares, no se específica cómo ésto será ejecutado.

Los cambios pueden ser impuestos a los militares desde afuera; sin embargo, a menos que el ímpetu tranformador se genere desde dentro de la institución militar, es improbable que tales cambios puedan lograr el impacto requerido. Hay muy pocos indicios de que la percepción de los militares en torno a su rol tradicional en la sociedad o sobre los políticos - y civiles- haya cambiado significativamente. Por el contrario, altos oficiales continúan viendo a la Fuerza Armada como la única institución que representa los intereses auténticos de la nación, en la tradición de la doctrina de la seguridad nacional. En declaraciones de oficiales de alto rango se afirma que las fuerzas armadas continuarán defendiendo el orden constitucional y que nunca se someterán a los designios de los que ellos consideran sus enemigos. Contrariamente a su nuevo rol constitucional, los militares afirman que éllos continuarán "sosteniendo las instituciones". (En Walter y Williams, 1992).

Los altos oficiales también tienen el concepto del ejército como la única fuerza cualificada para liderear el proceso nacional de reconstrucción. De hecho, desde el comienzo del cese de fuego los militares han estado realizando las tradicionales acciones cívicas, incluyendo reparación de infraestructura, salud pública, distribución y equipo médico y alfabetización. Incluso han invadido nuevas áreas como conservación del medio ambiente y reforestación. Esto se podría explicar por dos factores. En primer lugar, los militares estarían tratando de justificar su existencia después de la guerra, cuando su papel se está volviendo cada vez más irrelevante, máxime cuando no se vislumbra la posibilidad de conflictos con otros países. En segundo lugar, todas estas actividades entrarían dentro de la tradición militar de acción cívica con el objetivo de mantener su "clientela" tradicional en el país y legitimarse dentro de la población. ( Walter y Wiliams, O.C.).

Y es que con la disolución de la Guardia Nacional y la disolución de las unidades de defensa civil y las patrullas cantonales, la tarea de mantener el control sobre la población campesina se ha vuelto 
más dificultosa. Por ello, además de las acciones cívicas, las medidas contenidas en la nueva ley de servicio militar pretenderían garantizar una continua presencia de los militares en las áreas rurales. La nueva ley permite a los militares crear centros de reclutamiento a través de todo el país. Existe un consenso generalizado que estos nuevos centros servirán como mecanismos de control sobre la población rural, además de ser otra fuente de corrupción. Pero, adicionalmente, estos centros pueden permitir a las fuerzas armadas influir directamente en las futuras actividades electorales de los partidos políticos y en los resultados del proceso político mismo.

Los militares también muestran poca disposición para subordinarse al control civil. Por ejemplo, la nueva ley sobre servicio militar fue formulada y propuesta por el Ministro de Defensa sin contar con la opinión de los partidos políticos. El propósito de la ley fue debatido en la Asamblea Legislativa, pero no fue modificada significativamente.

Los altos oficiales del Alto Mando sostienen que es muy improbable que el presupuesto militar pueda ser debatido con detalle en el futuro próximo. Ellos argumentan que en El Salvador no existe la tradición de discutir el presupuesto militar; y sobre todo sostienen que los políticos no tienen experiencia en asuntos militares. Además, los políticos y los "subversivos" no son confiables para conocer los "secretos" militares. Sobre la posibilidad de que un civil ocupe la cartera de Defensa, éllos no lo ven necesario por el momento, además alegan de que un civil podría generar desconfianza y desunión dentro de la institución militar, sobre todo porque los políticos carecen de la experiencia y la educación política necesaria. En cualquier caso, un político como ministro de Defensa tendría que ser "respetuoso" de la institución castrense. (Ver Walter y Williams, O.C.).

Por lo menos hasta el presente, los esfuerzos de los militares por mantener su autonomía institucional reflejan su desprecio por los civiles sobre la base de que éstos no tienen el derecho ni la capacidad para intervenir en las cuestiones militares. Lo más probable es que los militares resistirán las medidas y las políticas que ellos consideren que atenten contra sus intereses fundamentales o substanciales, obstaculizando así la transformación de las relaciones civiles-militares en un dirección democratizadora que vaya re- 
duciendo sus prerrogativas y privilegios tradicionales acrecentados durante el conflicto militar.

En este sentido, es importante un mayor protagonismo de la sociedad civil en la realización de una multiplicidad de tareas para ir posibilitando un mayor y más efectivo control civil, reduciendo la influencia perniciosa de la Fuerza Armada en el proceso político y su control tradicional sobre la sociedad y el Estado.

En esta línea, las universidades y los institutos de investigación pueden hacer contribuciones importantes. Un permanente estudio sistemático sobre los militares es fundamental en el desarrollo de nuevas estrategias que vayan transformando las relaciones civico-militares tradicionales. Las universidades y centros de investigación pueden contribuir a modificar la conciencia colectiva sobre el problema del militarismo como obstáculo para la construcción de la democracia.

A nivel de sociedad política, una estrategia de los partidos políticos debe ser aumentar su capacidad de supervisión legislativa de los asuntos militares. Generalmente los diputados no tienen acceso a los detalles del presupuesto militar, limitando con ello las posibilidades de un debate serio en este tema. Las fracciones legislativas de los distintos partidos necesitan contar con especialistas en materia militar. Incluso con ellos se podría establecer un comité permanente legislativo sobre asuntos militares. Además, los partidos pueden contribuir a desarrollar una política militar. Por lo general, ningún partido ha propuesto nada en concreto sobre esta materia; la mayoría de ellos continúan con una visión muy estrecha sobre las relaciones civiles-militares, incidiendo en su poca capacidad de propuestas que puedan irlas transformando en la línea de la democratización.

Por otra parte, el gobierno puede asumir un liderazgo fundamental en la formulación de una alternativa de la misión de los militares y promover su profesionalismo democrático. Es importante que el gobierno apoye a aquellos oficiales que comparten esta visión. En este sentido, es importante romper el concepto que tienen lo militares de los políticos como incapaces e inefectivos. Como lo señalan varios estudios, un gobierno civil inefectivo es probable que induzca a los militares a asumir un rol político mayor. 
Por su parte, el propio ejército debe hacer un esfuerzo por transformarse, entendiendo que es más beneficioso para su permanencia y legitimidad, asumir un rol democrático, realizándose como una institución al servicio del pueblo y de la patria, cumpliendo así con el fin más noble de la profesión militar, que responde a una vocación más de servicio que a intereses utilitarios. En la Fuerza Armada debe prevalecer más el sentido de desprendimiento sobre cualquier ambición personal o interés lucrativo. "La profesión militar puede llevar consigo la ofrenda de la propia vida en defensa de intereses superiores, que no son los de una patria abstracta, sino los de una sociedad histórica de hombres, la cual ha depositado en ellos la tarea de defender y sostener la soberanía y la autodeterminación" (Ellacuría, 1984: 475-490).

Los militares deben acostumbrarse a verse como una parte de la sociedad y del Estado, cuyos derechos y obligaciones están perfectamente delimitados. Ver la carrera militar "como vía fácil de enriquecimiento, de prestigio o de poder político es ya una equivocación de principio que debe ser superada" (Ibidem). La vocación militar es una vocación singular cuya recompensa está más en la línea del servicio que del aprovechamiento propio.

Dado que los acuerdos de paz no afrontan directamente las raíces estructurales del conflicto, posponiendo la implementación de las transformaciones socio-económicas, por lo menos por ahora es importante ir asegurando la conformación de una genuina democracia política que ofrezca el marco para esa implementación. Esto pasa por resolver el persistente "nudo gordiano" del proceso político: la reestructuración a fondo de las fuerzas armadas salvadoreñas y su comportamiento político.

\section{Bibliografía}

Andino Martínez, Carlos, "El Estamento Militar en El Salvador", Revista ECA, julio-agosto 1979.

Andino Martínez, Carlos, "El estamento Militar Salvadoreño Redefinido", Revista ECA, mayo-junio, 1982.

Bacevich, A.J., et. al., American Military Policy in Small Wars; The Case of El Salvador, Washington, D.C., Pergamon-Brassey's International Defense Publishers, 1988.

Baloyra-Herp, Enrique, Reactionary Despotism in Central America", Journal of 
Latin American Studies.

Benítez Manaut, R., La Teoría Militar y la Guerra Civil en El Saloador, San Salvador, UCA editores, 1989.

Campos, Tomás R., "La Seguridad Nacional y la Constitución Salvadoreña", revista ECA, julio-agosto 1979.

Castro Morán, Mariano, Función Política del Ejército Salvadoreño en el Presente Siglo, San Salvador, UCA editores, 1989.

CINAS, "Centroamerica y Estados Unidos 1985", en Estados Unidos: perspectiva latinoamericana, cuadernos semestral del CIDE, México, 1986.

Echeverría, Santiago, “La Democratización del País como Principio de Solución al Conflicto Armado", Revista ECA, septiembre de 1990.

Ellacuría, Ignacio, "El Desmoronamiento de la Fachada Democrática", editorial de la revista ECA, mayo 1988.

Ellacuría, Ignacio, "Los Militares y la Paz Social", editorial de la revista ECA, 1984.

García, José Z., "Origins of Repressiveness or Moderation in the Militaries of El Salvador and Honduras", trabajo presentado en la reunión de la Western Political Science Association, San Diego California, Marzo de 1982.

Guidos Véjar, R. El Ascenso del Militarismo en El Salvador, San Salvador, UCA editores, 1980.

Huntington, Samuel P., Political Orden in Changing Societies, New Haven, Yale University Press, 1968.

Lafeber, W., Revoluciones Inevitables, San Salvador, UCA editores, 1989.

López Vallecillos, Italo, "Fuerzas Sociales y Cambio Social en El Salvador", Revista ECA, julio-agosto 1979.

Mariscal, Nicolás, "Militares y Reformismo en El Salvador", Revista ECA, enero-febreo, 1978.

Martin, P.P., Salvador of the Twentieth Century, London, 1911, citado por Guidos Véjar, o.c.

Millman, Joel. "El Salvador's Army: A Force Unto Itself", New York Time Magazine, December 10, 1989.

Monteforte Toledo, M., Centroamérica: Dependencia y Subdesarrollo, Vol.2, México, UNAM, 1972.

O'Donnell y Schmitter, Transiciones desde un Gobierno Autoritario, Tomo III y IV, Buenos Aires, Editorial Paidós, 1988.

Pérez Jr., Louis, "Armies of the Caribbean", trabajo presentado a la reunión anual de la Latin American Studies Association, Albuquerque, Nuevo México, abril 1985.

Perlmutter, The Military and Politic in Modern Times, New Haven, Yale University, 1977.

Przeworski, A., "La Democracia como Resultado Contingente de los Conflictos", Zona Abierta, abril-septiembre, 1986.

Ropp, Steve C., "Teoría sobre el Comportamiento de los Militares Centroamericanos", revista ECA, Mayo-Junio 1986.

Ropp, Steve C., "The Honduram Military in the Sociopolitical Evolution of Honduran State", The Americas, Vol. 30, No. 4, april 4, 1974.

Rouquié, Alain, The Military and the Satate in Latin América, Berkeley, University 
of California Press, 1987.

Schwartz, Benjamin, American Counterinsurgency Doctrine and El Salvador, Washington, D.C., Rand Corporation, 1991.

Stepan, Alfred, "The New Professionalism of Internal Warfare and Military Role Expansion", en Lowenthal, Armies and Politics in Latin America, New York, Holmes and Meir, 1976.

Torres Rivas, E., "Centroamerica: Guerra, Transición y Democracia" Revista ECA, octubre 1986.

Walter, Knut y Williams Philip, "The Military and Democratization in El Salvador", Sept. 27, 1992. (mimeo).

Wilson, E., The Crisis of National Integration in El Salvador, 1919-1935, 1970, citado por Guidos Véjar, o.c.

White, Alastair, El Salvador, San Salvador, UCA editores, 1983. 